\title{
Performance Evaluation of a Nanomaterial-Based Thermoelectric Generator with Tapered Legs
}

\author{
Marilyn A. Ebiringa ${ }^{1}$, JohnPaul Adimonyemma² and Chika Maduabuchi ${ }^{2, *}$ \\ ${ }^{1}$ Department of Food Science and Technology, Federal University of Agriculture, P.M.B. 2373, Makurdi, Nigeria \\ and ${ }^{2}$ Department of Mechanical Engineering, University of Nigeria, Nsukka 410001, Enugu, Nigeria.
}

\begin{abstract}
A thermoelectric generator (TEG) converts thermal energy to electricity using thermoelectric effects. The amount of electrical energy produced is dependent on the thermoelectric material properties. Researchers have applied nanomaterials to TEG systems to further improve the device's efficiency. Furthermore, the geometry of the thermoelectric legs has been varied from rectangular to trapezoidal and even X-cross sections to improve TEG's performance further. However, up to date, a nanomaterial TEG that uses tapered thermoelectric legs has not been developed before. The most efficient nanomaterial TEGs still make use of the conventional rectangular leg geometry. Hence, for the first time since the conception of nanostructured thermoelectrics, we introduce a trapezoidal shape configuration in the device design. The leg geometries were simulated using ANSYS software and the results were post-processed in the MATLAB environment. The results show that the power density of the nanoparticle X-leg TEG was 10 times greater than that of the traditional bulk material semiconductor X-leg TEG. In addition, the optimum leg geometry configuration in a nanomaterial-based TEG is dependent on the operating solar radiation intensity.
\end{abstract}

Keywords: Solar energy, Thermoelectric generator, Tapered leg geometry, Solar radiation, Nanomaterials, Solar power generation.

\section{INTRODUCTION}

Research aimed at increasing the efficiency of thermoelectric generators (TEGs) is increasing [1,2]. This is because of the profitable perks offered by these devices [3-5]. Nevertheless, in order to meet up with the performance output of photovoltaic cells, much work is still needed in improving the performance of thermoelectric generator systems [6-8].

An effective and economic technique of improving the efficiency of thermoelectric devices is by varying the TE leg geometry [9-11]. To this end, Ali et al. [12] proposed an innovative design of a segmented TEG with exponential variable area leg geometry configuration. They disclosed that the proposed leg geometry improved the overall performance obtained from the TEG with a uniform material. Lee et al. [13] discovered that the single-stage TEG with cylindrical leg geometry configuration provided the highest power output of 0.73 $W$ and efficiency of $13.2 \%$, while generating the least thermal stress of $0.694 \mathrm{GPa}$. Zhang et al. [14] found that maximum performance was obtained from an annular TEG when the cross-sectional area of the thermoelectric leg was kept constant. Erturun et al. [15] discovered that although the thermoelement leg spacing had a significant effect on the thermal stress and efficiency, its

\footnotetext{
*Address correspondence to this author at the Department of Mechanical Engineering, University of Nigeria, Nsukka, Nigeria;

E-mail: chika.maduabuchi.191341@unn.edu.ng
}

effect on the device power output was negligible. Thimont et al. [16] showed that hollow thermoelectric leg geometries provided higher performance than solid structure leg geometries. Wang et al. [17] showed that the maximum power output was generated by the $X$-leg TEG when the taper angle was $10^{\circ} \mathrm{C}$. Mohammad Siddique et al. [18] experimentally demonstrated that a trapezoidal shaped thermoelement generated 1.24 times more voltage than a rectangular leg TEG when exposed to a temperature gradient of $10^{\circ} \mathrm{C}$. OlivaresRobles [19] enhanced the efficiency and power output of a TEG using a segmented nanostructured trapezoidal shape TEG. In summary, it is seen that the use of variable area leg geometries provided higher performance than rectangular leg geometries. Till date, the investigated leg geometries include the trapezoidal, X-, cylindrical, triangular, octagonal and even hollow leg structures. However, the implication of using nanostructured thermoelectric materials in tapered pins is yet to be investigated since the material used is the traditional semiconductor, bismuth-telluride.

Another method of improving TEG efficiency is by reducing the thermal losses due to convection in the thermoelectric legs [20-22]. This problem can be solved by using modified nanostructured thermoelectric materials $[23,24]$. These nanomaterials can be used to fabricate the $n$-type and $p$-type legs of the TEG. Thus, enhancing the material dimensionless figure of merit, and ultimately, TEG efficiency [25-27]. Zhang et al. [28] generated a power density and electrical efficiency of 
$2.1 \mathrm{~W} / \mathrm{cm}^{2}$ and $5.3 \%$, respectively, from a nanostructured TEG applied to a micro combined heating and power application, operating under a temperature difference of $500^{\circ} \mathrm{C}$. Badillo-Ruiz et al. [29] concluded that nanostructured thermoelectric materials provided maximum efficiencies in the range of $7 \%-16 \%$, while the values obtained from conventional bulk semiconductors were $5 \%-8 \%$. Yanagisawa [30] obtained a $60 \%$ reduction in the thermal conductivity of the Silicon membrane by using a nano-patterning structure in place of the unpartnered one.

Conclusively, these papers show the use of nanomaterials in improving TEG performance. However, all these proposed devices have failed to simultaneously study the effects of variable area leg thermoelements and enhanced nanomaterials. This novel device arrangement might hold the key to further improvements in the device overall performance.

Therefore, a performance evaluation and optimisation of a TEG with nanomaterial-based variable area thermoelements have been conducted using ANSYS 2020 R2 software. Six leg geometry arrangements are studied under isoflux and convective boundaries. Also, the effects of the load resistance and solar radiation intensities on the TEG performance parameters were studied. The most important finding of this study is that the power density generated by the nanoparticle X-leg TEG was 10 times greater than that of the traditional bulk material semiconductor X-leg TEG. Finally, for the nanostructured TE materials, the use of an X-leg TEG generated the maximum power density of $5.8 \times 10^{6}$ $\mathrm{W} / \mathrm{m}^{3}$ at a solar intensity of 70 suns. However, the rectangular leg TEG produced a peak power density of $5.5 \times 10^{6} \mathrm{~W} / \mathrm{m}^{3}$ at a solar intensity of 120 suns. Thus, implying that, in a nanostructured thermoelectric material TEG, the optimum leg geometry configuration is dependent on the operating solar radiation intensity incident on the TEG hot junction.

\section{METHODOLOGY}

\subsection{System Description}

The various configurations of the three-dimensional models of the TEGs without the solar concentrator are shown in Fig. (1). The leg geometries considered in this study are the rectangular, trapezoidal and X-leg geometries. The trapezoidal and $X$-leg geometries have been selected due to their superior performance as reported in refs. [18,19,31,32]. Thus, Figs. (1a-f) illustrate the TEGs with rectangular legs, rectangular plus trapezoidal legs, rectangular plus X-legs, trapezoidal legs, trapezoidal plus $\mathrm{X}$-legs and $\mathrm{X}$-legs. These configurations have been made so as to determine the effects of leg asymmetry on the overall device performance. An asymmetric thermocouple is one that uses different leg geometries. The surface area of the thermoelectric module is $40 \times 40 \mathrm{~mm}^{2}$. The dimensions of a single rectangular, trapezoidal and $\mathrm{X}$-leg can be obtained from refs. [33,34].

The thermoelectric material used in the legs are nanomaterials comprising an n-type leg of $\mathrm{Bi}_{2} \mathrm{Te}_{3}$ (bismuth telluride) $+0.1 \mathrm{vol} \% \mathrm{SiC}$ (silicon carbide) nanoparticles [23] and a p-type leg of BiSbTe (bismuth antimony telluride) nanocrystalline bulk alloy [24].

\subsection{Thermoelectric Field Equations}

The three-dimensional steady-state equations that govern thermoelectric phenomena are given in vector form as $[20,35,36]$.

$$
\begin{aligned}
& \vec{\nabla} \mathrm{g}(S T \vec{J})-\vec{\nabla} \mathrm{g}(k \vec{\nabla} T)=U^{\prime \prime \prime} \\
& \vec{\nabla} \mathrm{g}\left(\frac{1}{\rho} \cdot S \vec{\nabla} T\right)+\vec{\nabla} \mathrm{g}\left(\frac{1}{\rho} \cdot \vec{\nabla} \varpi\right)=0
\end{aligned}
$$

where $S$ is the Seebeck coefficient, $T$ is the absolute temperature, $J$ is the current density, $k$ is the thermal conductivity, $U^{\prime \prime}$ is the internal heat generation per unit volume, $\rho$ is the electrical resistivity and $\varpi$ is the scalar electric field potential.

\subsection{Numerical Method and Boundary Conditions}

The solid three-dimensional models of the diverse TEGs were developed in Autodesk Inventor CAD software. The CAD models were imported to ANSYS Workbench package. The thermal-electrical solvers, utilising the Seebeck and Peltier effects, were coupled and initiated using steady-state default configurations. The material properties of the thermoelements were obtained from refs. $[19,23,24,33]$ and were imposed on the coupled solver interface. A mesh convergence study was implemented to obtain a power density of 2500 $\mathrm{kW} / \mathrm{m}^{3}$ when a very fine mesh size of $0.01 \mathrm{~mm}$ was used, corresponding to the generation of 268,934 elements. In order to define the three-dimensional thermal model, the following boundary conditions were imposed: 1) a solar radiation intensity of $50 \mathrm{~kW} / \mathrm{m}^{2}$ was placed on the TEG hot junction ceramic plate, 2) a convective film coefficient of $500 \mathrm{~W} / \mathrm{m}^{2} \mathrm{~K}$ was placed at the TEG cold junction ceramic plate, 3 ) the TEG was operated under matched load conditions (the external load resistance was matched to the temperature-dependent internal leg 
(a)

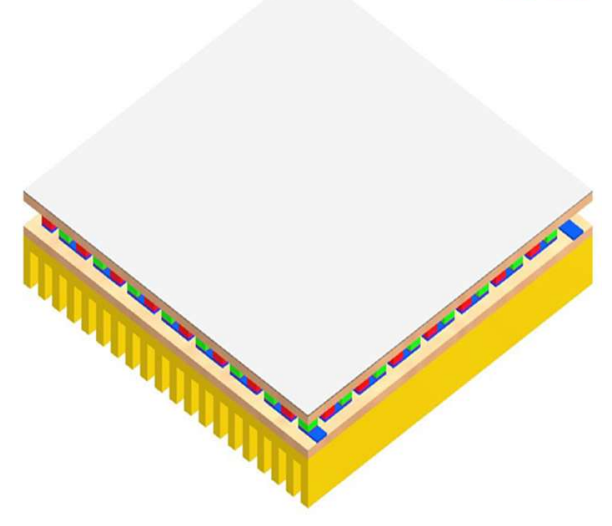

(c)

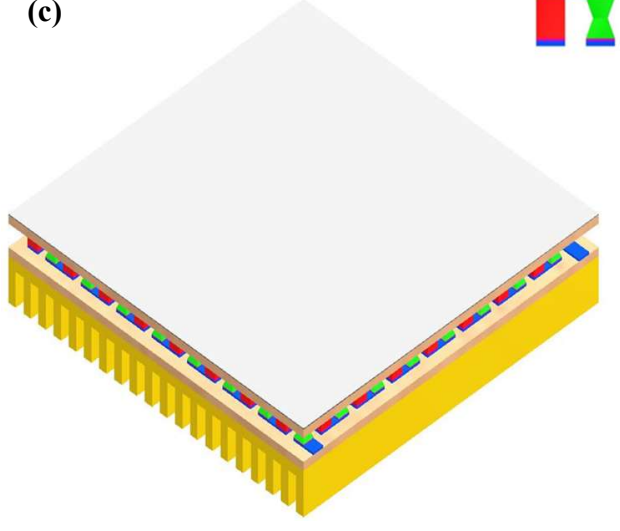

(e)

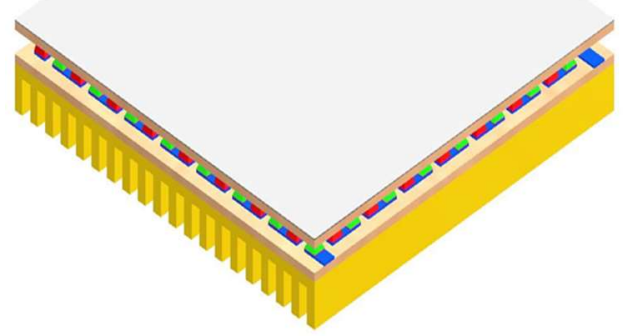

Figure 1: Proposed cases. (a) Case-1 (b) Case-2 (c) Case-3 (d) Case-4 (e) Case-5 and (f) Case-6. (b)

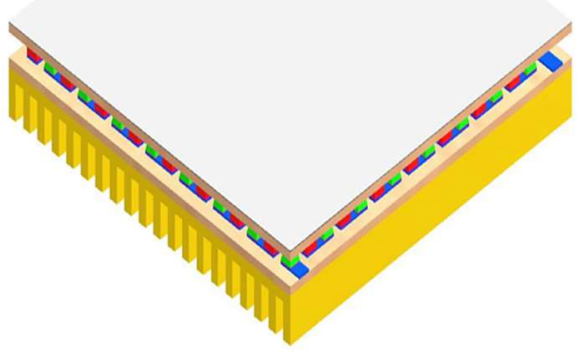

(d)

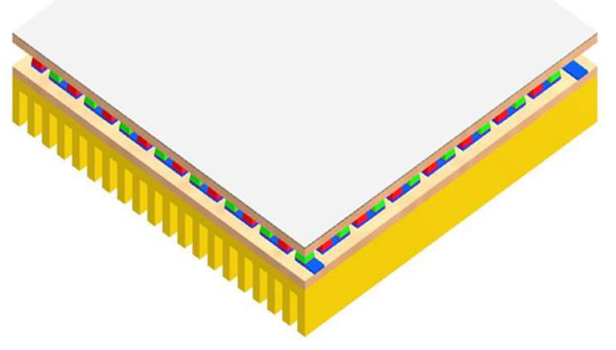

(f)
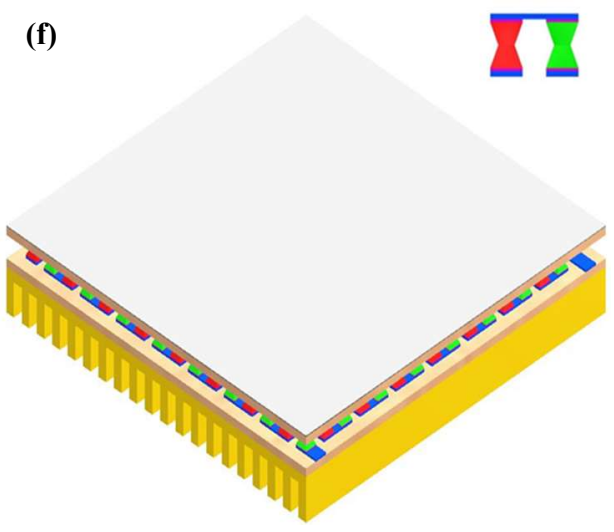

resistance), 4) a ground potential was placed at the $n$ leg face and 5) the walls of the TEG were assumed adiabatic.

\section{RESULTS AND DISCUSSIONS}

The results obtained from the numerical optimization of the various TEG models are presented herein. The parameters which are optimised are the load resistance and solar radiation intensity. Two sets of results are obtained using nanostructured materials and traditional bismuth-telluride. The output parameters that are recorded include the TEG power density and energy efficiency.

Thus, Figs. (2a-d) show that as the load resistance increases, the power density and energy efficiency increase first up to maximum values, followed by a 
(a)

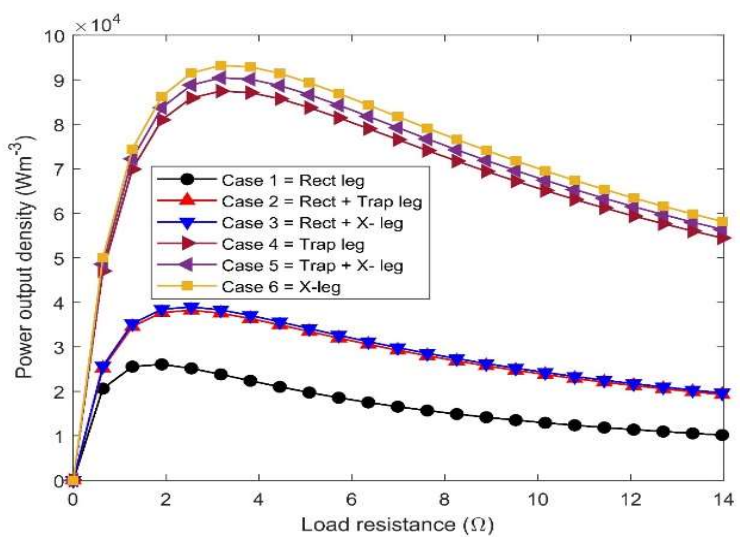

(c)

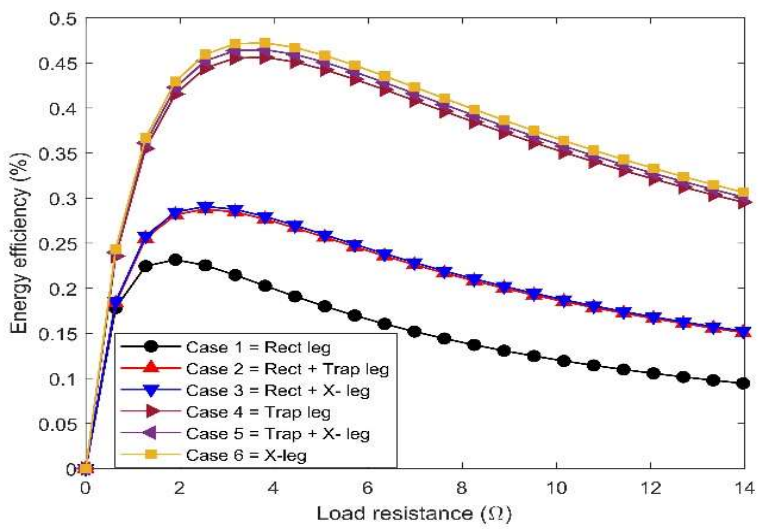

Figure 2: Effect of load resistance on systems' performance:

decline with a further increase in the load resistance. That is, maximum power density and energy efficiencies are obtained at an optimum load resistance in the TEG. Also, the optimum loads for maximum power density and energy efficiency in the various cases are slightly differrent. More specifically, the optimum load requirement tends towards the right as the case number is increased. This is due to the larger temperature difference generated by the cases with higher numbers. Thus, higher optimum loads will be needed in maximising the power output and energy efficiencies of the cases with variable leg geometries compared to those with conventional rectangular legs. These results agree with the findings of refs. [37,38].

In addition, the effect of thermoelectric materials on the overall TEG performance is shown. Figs. (2a, c) and (2b, d) depict the power density and energy efficiencies obtained from the nanomaterial and traditional bismuthtelluride material, respectively. It is observed that under the same operating conditions, the nanomaterial produced a better overall performance compared to the traditional bismuth-telluride material. This is due to its (b)

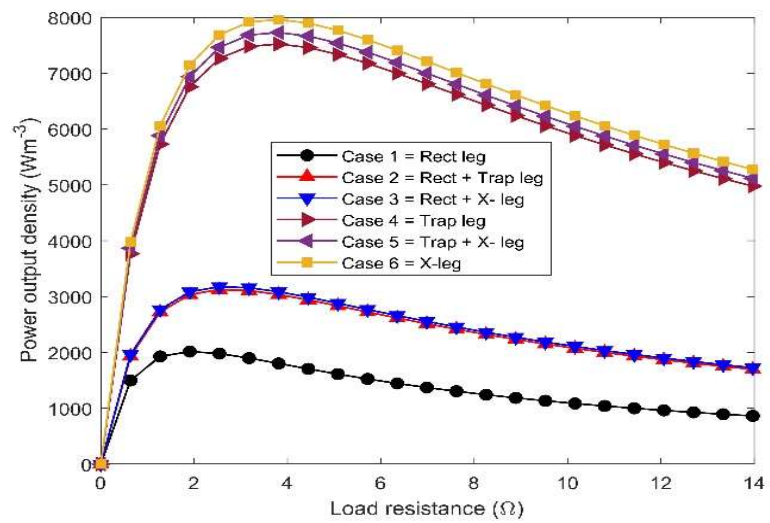

(d)

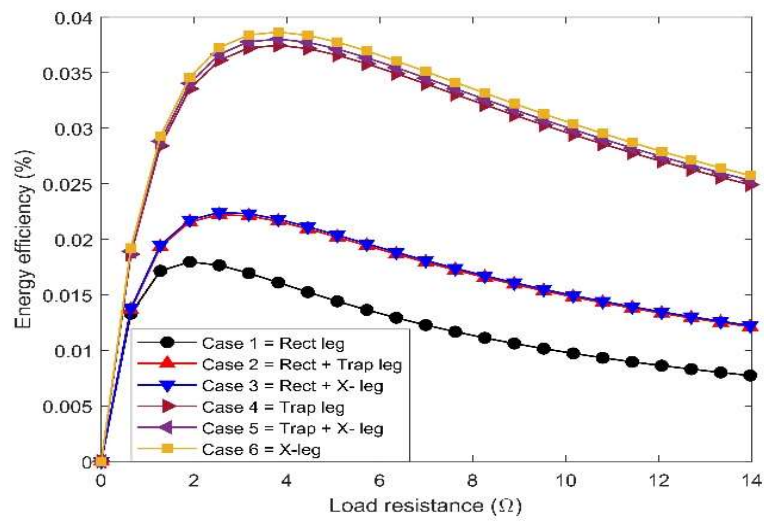

(a, c) nanomaterials $(\mathbf{b}, \mathbf{d})$ traditional material.

higher dimensionless figure of merit. Also, it provides a relatively higher thermal stability in its thermoelectric material properties. This allows it to still produce higher power output and efficiency at higher temperatures. The values obtained show that for case 6 , at an optimum load resistance of $3.175 \Omega$, the nanomaterial-based TEG produces a power density of $93.2 \mathrm{~kW} / \mathrm{m}^{3}$, while the traditional material-based TEG produces $7.68 \mathrm{~kW} / \mathrm{m}^{3}$. Also, the energy efficiencies obtained for the former and latter TEGs are $0.47 \%$ and $0.038 \%$. This indicates a $91.76 \%$ and $91.91 \%$ increase in the power density and energy efficiency of the traditional material-based TEG when the nanomaterial-based TEG is used instead.

In addition, the effect of solar radiation intensity on the power density and energy efficiency of the nanomaterial-type TEGs is shown in Figs. (3a-b), respectively. The plots reveal that increasing the solar radiation intensity results in a corresponding increase in the TEG power density and energy efficiency up to a maximum value before decreasing with a further increase in the solar radiation intensity. This means that there are optimum solar radiation intensities at which maximum 
(a)

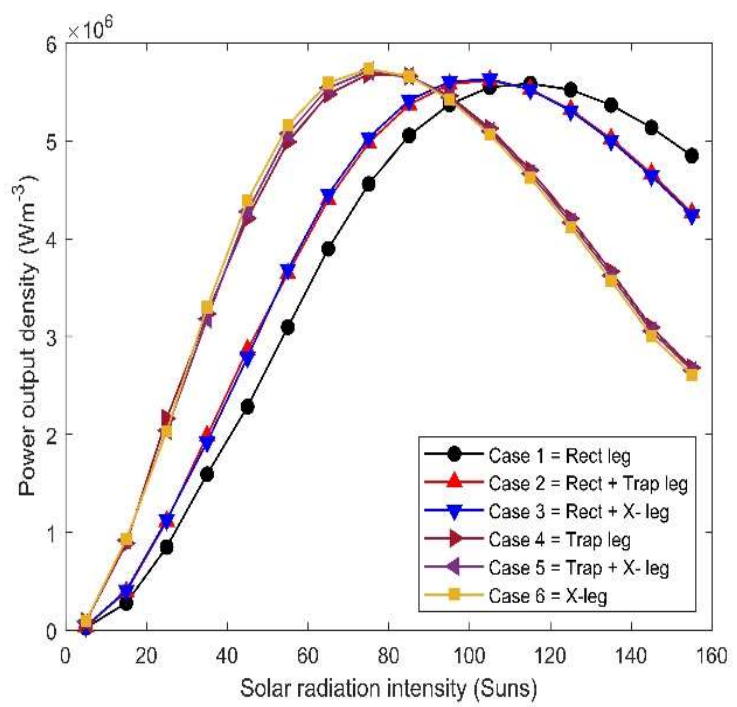

(b)

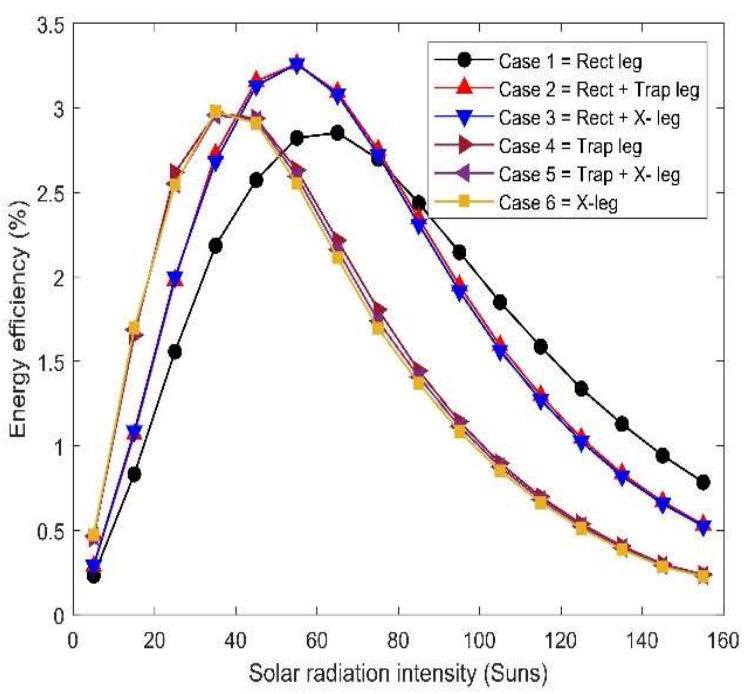

Figure 3: Effect of solar radiation intensity on nanomaterial TEG's performance: (a) power output density (b) energy efficiency.

power and efficiency are obtained from a TEG. Firstly, the optimum solar radiation intensities needed to maximise the power densities and energy efficiencies are different. Secondly, the optimum solar flux for maximum power and efficiencies in the six TEGs are different. Also, the optimum leg geometry for maximum power in a TEG is dependent on the operating solar flux. That is, under various fluxes, different optimum leg geometries are obtained.

For instance, Fig. (3a) shows that at a solar flux of 45 suns, the power densities obtained from case 1-6 are $2280 \mathrm{~kW} / \mathrm{m}^{3}, 2870 \mathrm{~kW} / \mathrm{m}^{3}, 2790 \mathrm{~kW} / \mathrm{m}^{3}, 4210 \mathrm{~kW} / \mathrm{m}^{3}$, $4280 \mathrm{~kW} / \mathrm{m}^{3}$ and $4390 \mathrm{~kW} / \mathrm{m}^{3}$, respectively. Thus, the best leg geometry is the X-leg geometry while the nonoptimal leg geometry is the rectangular leg. Meanwhile, at a solar flux of 155 suns, the power densities of cases 1-6 are $4850 \mathrm{~kW} / \mathrm{m}^{3}, 4270 \mathrm{~kW} / \mathrm{m}^{3}, 4240 \mathrm{~kW} / \mathrm{m}^{3}, 2680$ $\mathrm{kW} / \mathrm{m}^{3}, 2660 \mathrm{~kW} / \mathrm{m}^{3}$ and $2610 \mathrm{~kW} / \mathrm{m}^{3}$ respectively. Hence, the optimum leg geometry is the rectangular leg, while the non-optimal leg geometry is the X-leg geometry. This implies that the X-leg geometry is the optimum leg geometry under low solar fluxes, while the rectangular leg geometry is the optimum leg geometry under high solar radiation intensities.

\section{CONCLUSIONS AND FUTURE WORK}

A novel TEG employing nanostructured-tapered pins is modelled and optimized on ANSYS 2020 R2 software. The variable area leg geometries considered are the rectangular, trapezoidal and X-leg geometries. The effects of crucial operating parameters, such as the load resistance and solar radiation intensity, on the overall TEG performance, have been studied. The key findings of this study are as follows:

- Results indicate that under the same operating boundary conditions, the power density and energy efficiency obtained from the nanoparticle X-leg TEG was 10 times greater than that of the traditional bulk material semiconductor X-leg TEG. This was a result of the higher thermoelectric figure of merit produced by the nanostructured material relative to the traditional bulk material semiconductor, Bismuth-Telluride.

- In addition, for the nanostructured thermoelectric materials, the use of an X-leg TEG generated the maximum power density of $5.8 \times 10^{6} \mathrm{~W} / \mathrm{m}^{3}$ at a solar intensity of 70 suns. However, the rectangular leg TEG produced a peak power density of $5.5 \times 10^{6}$ $\mathrm{W} / \mathrm{m}^{3}$ at a solar intensity of 120 suns. This revealed a $5.45 \%$ enhancement in the power density of the rectangular leg TEG as a result of using X-leg geometries in a nanostructured material configuration.

- Finally, it was discovered that in a nanostructured thermoelectric material TEG, the optimum leg geometry configuration is dependent on the operating solar radiation intensity incident on the TEG hot junction. Thus, for a high solar flux application, the rectangular cross-section becomes the best geometry. However, in the case of a low solar flux application, the $\mathrm{X}$-leg (variable area leg) geometry 
becomes the optimum geometry.

- Although the present study offers new insights on the use of nanostructured tapered pins in TEGs, there is still much work to be done in this area. For instance, a mechanical study on the reliability of the optimum nanomaterial X-leg geometry TEG is yet to be conducted. Also, a parametric investigation on other operating parameters such as the convective film coefficient, hot and cold junction temperatures and the geometric parameter is yet to be studied. These will be the focus of future studies in this area.

\section{ACKNOWLEDGMENTS}

The authors are grateful to the reviewers for their constructive comments which improved the quality and presentation of this work.

\section{REFERENCES}

[1] Wu S, Zhang Y-C, Xia L. Conceptual design and performance analysis of concentrated solar - driven TIC / AMTEC / TEG hybrid system. Int J Energy Res 2018; 1-13. https://doi.org/10.1002/er.4209.

[2] Vikhor LN, Anatychuk LI. Generator modules of segmented thermoelements. Energy Convers Manag 2009; 50: 2366-72. https://doi.org/10.1016/j.enconman.2009.05.020.

[3] Sudharshan KY, Kumar VP, Barshilia HC. Performance evaluation of a thermally concentrated solar thermo-electric generator without optical concentration. Sol Energy Mater Sol Cells 2016; 157: 93-100. https://doi.org/10.1016/j.solmat.2016.05.033.

[4] Moreno RJ. Harvesting Waste Thermal Energy From Military Systems. Naval Postgraduate School, 2019.

[5] Zaman HU, Shourov CE, Al Mahmood A, Siddique NEA. Conversion of wasted heat energy into electrical energy using TEG. 2017 IEEE 7th Annu Comput Commun Work Conf CCWC 20172017. https://doi.org/10.1109/CCWC.2017.7868452.

[6] Fraisse G, Ramousse J, Sgorlon D, Goupil C. Comparison of different modeling approaches for thermoelectric elements. Energy Convers Manag 2013; 65: 351-6.

https://doi.org/10.1016/j.enconman.2012.08.022.

[7] Muthu G, Shanmugam S, Veerappan A. Theoretical and Experimental Study on a Thermoelectric Generator Using Concentrated Solar Thermal Energy. J Electron Mater 2019; 48: 2876-85. https://doi.org/10.1007/s11664-019-07024-w.

[8] Du CY, Wen C Da. Experimental investigation and numerical analysis for one-stage thermoelectric cooler considering Thomson effect. Int J Heat Mass Transf 2011; 54: 4875-84. https://doi.org/10.1016/j.ijheatmasstransfer.2011.06.043.

[9] He H, Liu W, Wu Y, Rong M, Zhao P, Tang X. An approximate and efficient characterization method for temperaturedependent parameters of thermoelectric modules. Energy Convers Manag 2019; 180: 584-97. https://doi.org/10.1016/j.enconman.2018.11.002.

[10] Wang XD, Huang YX, Cheng $\mathrm{CH}$, Ta-Wei Lin D, Kang CH. A three-dimensional numerical modeling of thermoelectric device with consideration of coupling of temperature field and electric potential field. Energy 2012; 47: 488-97. https://doi.org/10.1016/j.energy.2012.09.019.

[11] Karthick K, Suresh S, Joy GC, Dhanuskodi R. Experimental investigation of solar reversible power generation in
Thermoelectric Generator (TEG) using thermal energy storage. Energy Sustain Dev 2019; 48: 107-14.

https://doi.org/10.1016/j.esd.2018.11.002.

[12] Ali H, Yilbas BS, Al-Sharafi A. Segmented thermoelectric generator: exponential area variation in leg. Int $\mathrm{J}$ Energy Res 2018; 42: 477-89. https://doi.org/10.1002/er.3825.

[13] Lee M-Y, Seo J, Lee H, Garud KS. Power Generation, Efficiency and Thermal Stress of Thermoelectric Module with Leg Geometry, Material, Segmentation and Two-Stage Arrangement. Symmetry (Basel) 2020; 12: 786.

https://doi.org/10.3390/sym12050786.

[14] Zhang AB, Wang BL, Pang DD, Chen JB, Wang J, Du JK. In fl uence of leg geometry con fi guration and contact resistance on the performance of annular thermoelectric generators. Energy Convers Manag 2018; 166: 337-42.

https://doi.org/10.1016/j.enconman.2018.04.042.

[15] Erturun U, Erermis K, Mossi K. Influence of leg sizing and spacing on power generation and thermal stresses of thermoelectric devices. Appl Energy 2015; 159: 19-27. https://doi.org/10.1016/j.apenergy.2015.08.112.

[16] Thimont $\mathrm{Y}$, LeBlanc S. The impact of thermoelectric leg geometries on thermal resistance and power output. J Appl Phys 2019; 126: 095101. https://doi.org/10.1063/1.5115044.

[17] Wang R, Meng Z, Luo D, Yu W, Zhou W. A Comprehensive Study on X-Type Thermoelectric Generator Modules. J Electron Mater 2020; 49: 4343-54.

https://doi.org/10.1007/s11664-020-08152-4.

[18] Mohammad Siddique AR, Mahmud S, Heyst B Van. Performance comparison between rectangular and trapezoidal- shaped thermoelectric legs manufactured by a dispenser printing technique. Energy 2020; 196: 1-14.

https://doi.org/10.1016/j.energy.2020.117089.

[19] Olivares-Robles MA, Badillo-Ruiz CA, Ruiz-Ortega PE. A comprehensive analysis on nanostructured materials in a thermoelectric micro-system based on geometric shape, segmentation structure and load resistance. Sci Rep 2020; 10: 21659. https://doi.org/10.1038/s41598-020-78770-9.

[20] El-Desouky A, Carter M, Mahmoudi M, Elwany A, LeBlanc S. Influences of energy density on microstructure and consolidation of selective laser melted bismuth telluride thermoelectric powder. J Manuf Process 2017; 25: 411-7. https://doi.org/10.1016/j.jmapro.2016.12.008.

[21] Al-Habahbeh OM, Mohammad A, Al-khalidi A, Khanfer M Obeid M. Design optimization of a large-scale thermoelectric generator. J King Saud Univ - Eng Sci 2018; 30: 177-82. https://doi.org/10.1016/j.jksues.2016.01.007.

[22] Ali H, Sami B. Innovative design of a thermoelectric generator of extended legs with tapering and segmented pin configuration: Thermal performance analysis. Appl Therm Eng 2017; 123: 74-91.

https://doi.org/10.1016/j.applthermaleng.2017.05.066.

[23] Zhao L-D, Zhang B-P, Li J-F, Zhou M, Liu W-S, Liu J. Thermoelectric and mechanical properties of nano-SiCdispersed $\mathrm{Bi} 2 \mathrm{Te} 3$ fabricated by mechanical alloying and spark plasma sintering. J Alloys Compd 2008; 455: 259-64. https://doi.org/10.1016/j.jallcom.2007.01.015.

[24] Poudel B, Hao Q, Ma Y, Lan Y, Minnich A, Yu B, et al. HighThermoelectric Performance of Nanostructured Bismuth Antimony Telluride Bulk Alloys. Science (80- ) 2008; 320: 6348. https://doi.org/10.1126/science.1156446.

[25] Maduabuchi CC, Mgbemene CA, Ibeagwu OI. Thermally Induced Delamination of PV-TEG: Implication of Leg's Joule and Thomson Heating. J Electron Mater 2020; 49: 6417-27. https://doi.org/10.1007/s11664-020-08390-6.

[26] Ibeagwu OI, Eke MN, Maduabuchi CC, Mgbemene CA, Aka T V. Particle Overlay Obstruction Modelling, Parametric and Output Characteristics Evaluation of a Photovoltaic System. Niger Res J Eng Environ Sci 2020; 5: 679-93. 
[27] Zhang $\mathrm{Y}$, Wang $\mathrm{X}$, Cleary $\mathrm{M}$, Schoensee L, Kempf $\mathrm{N}$, Richardson J. High-performance nanostructured thermoelectric generators for micro combined heat and power systems. Appl Therm Eng 2016; 96: 83-7.

https://doi.org/10.1016/j.applthermaleng.2015.11.064.

[28] Badillo-Ruiz CA, Olivares-Robles MA, Chanona-Perez JJ. Design of nano-structured micro-thermoelectric generator: Load resistance and inflections in the efficiency. Entropy 2019; 21. https://doi.org/10.3390/e21030224.

[29] Yanagisawa R, Tsujii N, Mori T, Ruther P, Paul O, Nomura M. Nanostructured planar-type uni-leg $\mathrm{Si}$ thermoelectric generators. Appl Phys Express 2020; 13: 095001. https://doi.org/10.35848/1882-0786/aba5c4.

[30] Ali H, Yilbas BS, Sahin AZ. Exergy analysis of a thermoelectric power generator: influence of bi-tapered pin geometry on device characteristics. Int J Exergy 2015;16:53-71. https://doi.org/10.1504/IJEX.2015.067299.

[31] Lamba R, Manikandan S, Kaushik SC, Tyagi SK. Thermodynamic modelling and performance optimization of trapezoidal thermoelectric cooler using genetic algorithm. Therm Sci Eng Prog 2018; 6: 236-50. https://doi.org/10.1016/j.tsep.2018.04.010.

[32] Maduabuchi C, Singh S, Ozoegwu C, Njoku H, Eke M. The Combined Impacts of Leg Geometry Configuration and MultiStaging on the Exergetic Performance of Thermoelectric Modules in a Solar Thermoelectric Generator. J Energy Resour Technol 2022; 144: 1-23. https://doi.org/10.1115/1.4051648.
[33] Nemati A, Nami H, Yari M, Ranjbar F. Effet de la géométrie et des courants appliqués sur l'exergie et la performance exergoéconomique d'un refroidisseur thermoélectrique bi-étagé en cascade. Int J Refrig 2018; 85: 1-12. https://doi.org/10.1016/j.ijrefrig.2017.09.006.

[34] Xiong B, Chen L, Meng F, Sun F. Modeling and performance analysis of a two-stage thermoelectric energy harvesting system from blast furnace slag water waste heat. Energy 2014; 77:562-9. https://doi.org/10.1016/j.energy.2014.09.037.

[35] Kaushik SC, Manikandan S. The influence of Thomson effect in the energy and exergy efficiency of an annular thermoelectric generator. Energy Convers Manag 2015; 72: 57-64. https://doi.org/10.1016/j.enconman.2015.06.037.

[36] Ranjan M, Maiti T. Device modeling and performance optimization of thermoelectric generators under isothermal and isoflux heat source condition. J Power Sources 2020; 480: 228867. https://doi.org/10.1016/j.jpowsour.2020.228867.

[37] Jaworski M, Bednarczyk M, Czachor M. Experimental investigation of thermoelectric generator (TEG) with PCM module. Appl Therm Eng 2016; 96: 527-33. https://doi.org/10.1016/j.applthermaleng.2015.12.005.

[38] Tan L, Singh R, Date A, Akbarzadeh A. Thermal Performance of Two-Phase Closed Thermosyphon in Application of Concentrated Thermoelectric Power Generator Using Phase Change Material Thermal Storage. Front Heat Pipes 2012; 2. https://doi.org/10.5098/fhp.v2.4.3001.

Received on 03-12-2020

Accepted on $26-12-2020$

Published on 30-12-2020

DOI: http: //dx.doi.org/10.15377/2409-5818.2020.07.5

(C) 2020 Ebiringa et al.; Avanti Publishers.

This is an open access article licensed under the terms of the Creative Commons Attribution Non-Commercial License (http: //creativecommons.org/licenses/by-nc/3.0/) which permits unrestricted, non-commercial use, distribution and reproduction in any medium, provided the work is properly cited. 